\title{
A Relational Ecology of Photographic Practices
}

\author{
Jacqui Knight \\ CogNovo \\ Transtechnology Research \\ Plymouth University, UK \\ jacqui.knight@plymouth.ac.uk
}

Received 24 May 2017; accepted 26 September 2017; published 21 November 2017.

\begin{abstract}
This paper proposes a relational history of media artifacts, which decentralizes the dominance of the photographer or filmmaker as the absolute author of the work. It adds an alternative account to understanding the creative process and the subsequent study of media forms by discussing film and photographic practices as the reciprocal affective relationship between the maker, their intentions, materials, technologies, non-human agents and the environment. By reorganizing the anthropocentrism of art historical narratives, which typically exclude corporeality and materiality as drivers of human history, we are able to discuss the complex dynamic meshwork of determinants that bring photographic artifacts into existence: the lived, animate, vital materialism at once emergent and mixing of different causalities and temporalities.

Within this position, I will provoke discussions of cognition and photography by recalibrating the moment of acting to a model that recognizes a distributed nature of human action into the material world of things. This new materialist position has repercussions for the way we understand processes of creativity and the emergence of media artifacts-seeing these as always already entangled and enmeshed across various corporeal and material, platforms and scales.

This paper uses photography as a case study to discuss the broader theme of co-creation between humans, machines and the environment. Using documentary evidence from the archive, I sustain this argument by making a close reading of a particular photographer's contact sheet, which shows up some of the dynamics of the relational meshwork playing upon the photographer in the field. Through this reading we can
\end{abstract}


begin to think about the implications for the way we understand the emerging aesthetic discourse of technological photographic practices and, more broadly, the cocreative domains of all human activity.

Keywords: decisive moment; distributed cognition; entanglement; new materialism; relational ecologies.

In traditional accounts, photography's mode of making gives the illusion of a seamless continuity between the world and its representation, producing the illusion that the world is co-operating with the photographer. Photography's innate relationship to indexicality has reinforced this. Contrary to the dominant literature which places the all-intentional photographer as the central driver of photographic artifacts, I want to consider the reverse aspect of this-that photographs can show up how uncooperative the world can be, drawing attention to the importance of thinking about creativity as contingent to a world that always wants to do its own thing.

What is offered here is another way to look at photographic material that recognizes the reciprocal affective relationships between photographer, apparatus and subjects by adopting new materialist theories that acknowledge the agency in the creative process as variously distributed and possessed in relational meshworks of persons and things. Photographs do not simply appear; they are co-produced by a complex, transformational meshwork of determinants that include the photographer, their apparatus, culture and the world.

With its acknowledgement of agential matter, material forces and physical processes, new materialism and similar object-orientated theories question the anthropocentric narrative that has underpinned our view of humans in the world since enlightenment, "a view that posits humans as makers of the world and the world as a source for human endeavours" (Barret \& Bolt, 2012, p. 3). Thinking about these theories in relation to creative activity offers an alternative narrative to the received history by which the study of media forms have typically been positioned.

In recognizing and refiguring the "organizm" the photographer works within, this study proposes a relational ecology of film and photographic practices. Through a close reading of photographic artifacts, the traces of the apparatus and some of the environmental conditions the photographer works within, we are afforded a direct insight into the relationship between affect and effect, seen in the subsequent photographic image.

Although using historical examples from documentary photography, it is intended this study would point to the broader theme of co-creation between humans, machines and the environment. In particular, this approach also suggests a way to understand the scope and limitations of the diverse spectrum of technological photographic practices that are calling for an alternative photographic theory since they displace human agency and we can no longer talk about the different uses of eye and hand to observe and record. 


\section{The Meshwork}

The idea of a meshwork as Tim Ingold (2007, p. 82) describes it, is a relational field, not of static, interconnected points as in a network, but of interwoven lines, a meshwork of interaction, a system that is woven together by a web of movements. Ingold's meshwork of entangled lines of growth and movement is therefore distinct from a network as in Latour's Actor Network Theory (ANT): "action is not so much the result of an agency that is distributed around the network from node to node, but emerges from the interplay of forces that are conducted along the lines of the meshwork" (Ingold, as cited in Knappett \& Malafouris, 2008, p. 212). In a meshwork it is the entangled relationships that are more important than the transportation of heterogeneous bits of information from node to node.

If we take the view that all things are enmeshed and entangled in a dynamic emergent system, this means the photographer works with and against many other agential, affective forces such as: the camera with its many program settings, the conventions of visual culture, a dynamic world of objects and other people and nonhuman entities which have their own temporalities and so on. Within Ingold's animistic ontology, we see that enskilled photographers and filmmakers do not propel themselves across a ready-made world but rather move through a world-information, along the lines of their relationships.

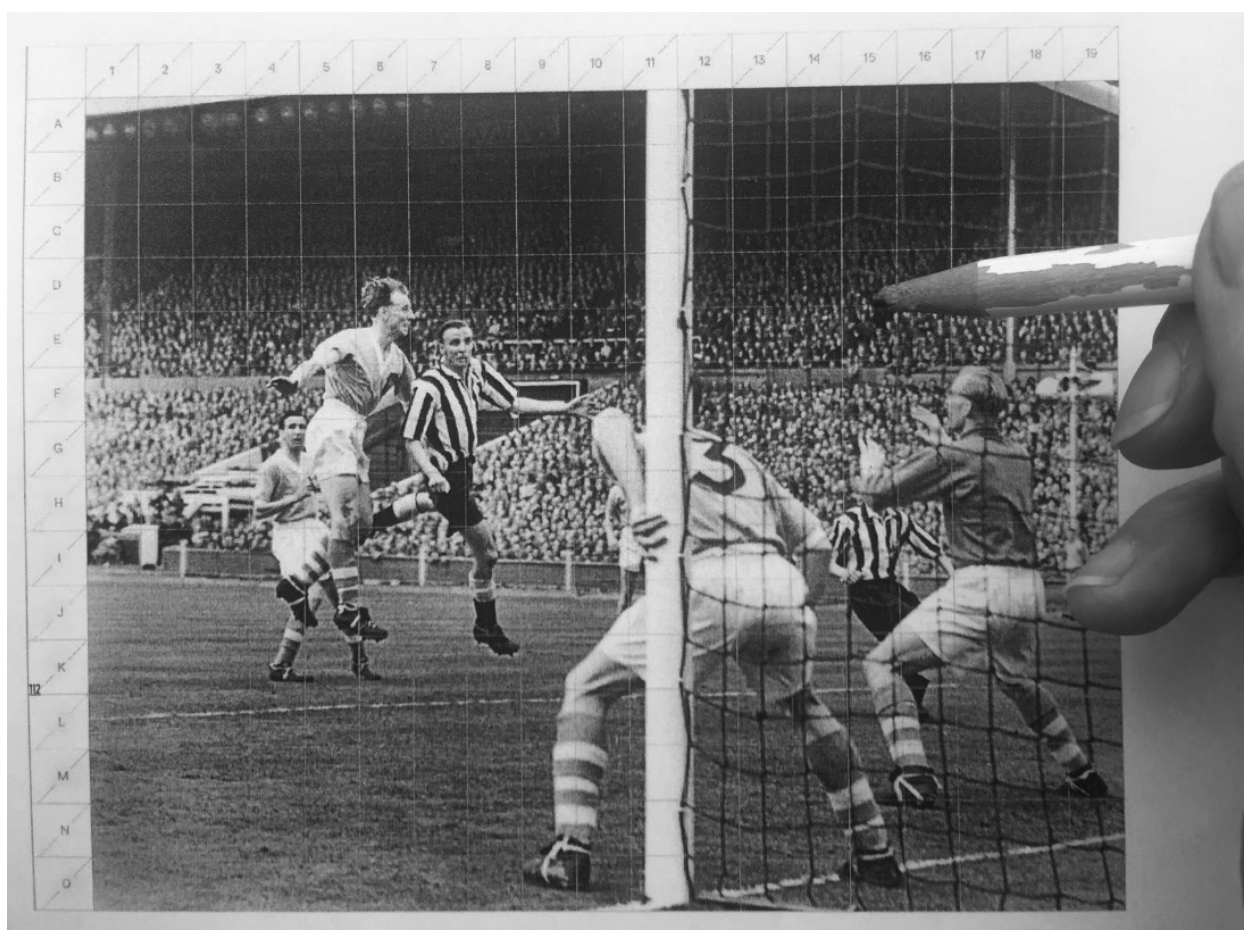

Figure 1. Spot the Ball game. Image rights with the author. 
Using as an example a game of Spot the Ball, I want to briefly focus attention on the kind of specific relationships in a dynamic meshwork. In its 1970s heyday, Spot the Ball was played by three million people a week (Cocozza, 2015). To win, a player has to mark the exact position of a missing ball, erased from a photograph of a liveaction football game. The photograph freezes the meshwork for us to analyze it, but one actant, the ball, is removed. We could say the absent ball is the organizing principle in the meshwork. In order to decipher the position of the ball, the game requires you to forensically study the relationships between not only the players but every tangible and intangible object in relationship to one another: the football pitch, the goal, shadows, eye contact, gestures, gravity, imagined speed, weight, negative spaces, perspectives, the rules of the game, we might also identify the particular style and tactics of known players and so on. The only way to make any guesstimate is to study the entanglement and interrelations of both human and non-human entities, rather than exclusively examining the inter-actions between humans.

In 2015, several newspaper articles questioned why this hugely popular game hadn't had a jackpot winner in ten years. You'd think one out of three million people and a cash prize to motivate and sharpen the attention might have pinpointed the one missing element in the meshwork. ${ }^{1}$

A player of Spot the Ball laments: "it was always hard. The pen nib was too thick, usually two players were looking in different directions. I don't remember any of us winning" (Cocozza, 2015).

Of course, the game is too difficult because trying to understand all the determinants in a meshwork is problematic, particularly when you are not part of it. The meshwork is its own infinite organism and the players within it are anticipating the future in different ways, eyes and heads in different directions. As indicated in Ingold's diagram, there appears to be no focal point, there are many possible streams of interactions, with differing affective hierarchies at different moments.

\footnotetext{
${ }^{1}$ According to the Gambling Commission, newspapers were able to run football competitions like Spot the Ball legally as a prize competition rather than a lottery, as long as it was without charge and the competition required "an element of skill, knowledge or judgment that is reasonably likely to prevent a significant proportion of people who wish to participate from doing so, or prevent a significant proportion of people who participate from receiving a prize." For example, if a panel of judges determine the position of the ball and participants have to apply judgment, skill or knowledge to match their own decision of where the ball is with that of the panel, it is more likely to be a prize competition than a lottery.
} 


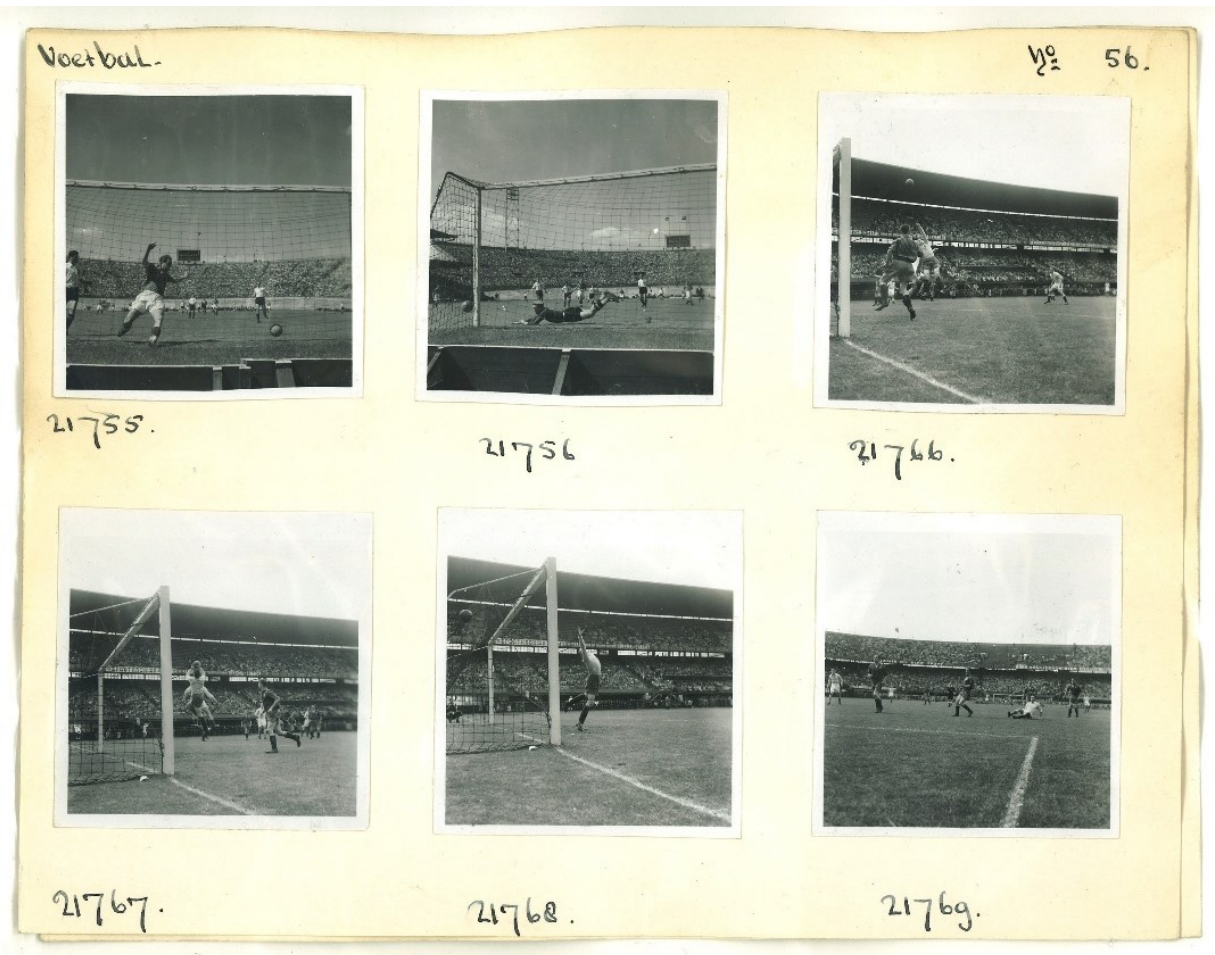

Figure 2. Voetbal contact print no.56 by Kees Molkenboer. (C) Kees Molkenboer / Nederlands Fotomuseum, Rotterdam.

A series of contact prints made by Dutch photojournalist Kees Molkenboer features two separate football matches taken on the same day, February 25, 1952, at the Olympic Stadium, Amsterdam, and Feyenoord Stadium, Rotterdam. In making a close reading of these contact prints, it is possible to trace some of the determinants within a dynamic meshwork and to understand the co-authorship of the photographer's creative process with technology, culture, and other non-human agential matter, material forces and physical processes.

This method will not explain "why" or "how" a meshwork takes the form that it does, nor can it disclose how to harness and measure the conditions of a creative moment in order to understand the mechanisms of it. Rather, this is a method for understanding the manifestations of human engagement with matter, exploring the relational ties within a meshwork when human and non-human meshworks come together to act as a whole. For photography, this approach reconsiders the impression that the photographer creates a representation of the world that is separate and stands apart from the photographer. When it is recognized that the world is an active agent, the world as an agent is playing a role in the co-creation of the artifact. 
In this regard, the photographers contact print or proof sheet are valuable artifacts that not only record the action of the camera but also provide evidence of some of the intentions and decision-making processes of the photographer "with and in the field." We are afforded something of the photographers self-corrective thought processes as he or she reconciles their experience of the world. But in as much as the typical contact sheet provides a record in time, it can also reveal the sequence in which an event unfolded and a trace of the relational meshwork of determinants that press upon the photographer in each given moment; the process of interaction that does not privilege one between the photographer, their apparatus, other subjects and the world.

When I am looking at Molkenboer's contact prints, my primary understanding is that these photographs were manufactured by a visually intelligent mind with technical competence, experience, sensibility and understanding. But what doesn't normally get factored into the media history texts is the degree to which the instrument itself is in dialogue with the visual intelligence of the photographer and has some agency in determining the final image. The camera is not simply procedural and cultural, but ontological; it has a being of its own, and seeing is a consensual action with the apparatus.

Molkenboer preferred to use a Rolleiflex camera which is used by holding it at the waist and looking down into the viewfinder mounted on top of the camera. This camera, a twin lens reflex, has two lenses: one which gives you what you see when you look through the viewfinder, and the bottom lens that takes the picture. This means there is a slight offset between what the photographer frames through the viewfinder and what the camera photographs. For Kees Molkenboer, accounting for this offset would have made the difference between capturing and not capturing the fastmoving action of the game. It is precisely in these moments of recalibration, in accounting for something, such as the limitations of the technology, is where a certain embodied symbiosis starts to happen between the photographer and the camera, an extended cognition, a thinking that occurs through and with the apparatus.

Additionally, using this camera, the body of the photographer is implicated in this way of seeing and composing. The camera is held at the waist, tilted slightly up towards the action. The photographer works by looking up to locate the action, then looks down to quickly frame it in the viewfinder, working to establishing a composition that is felt as much as seen. 


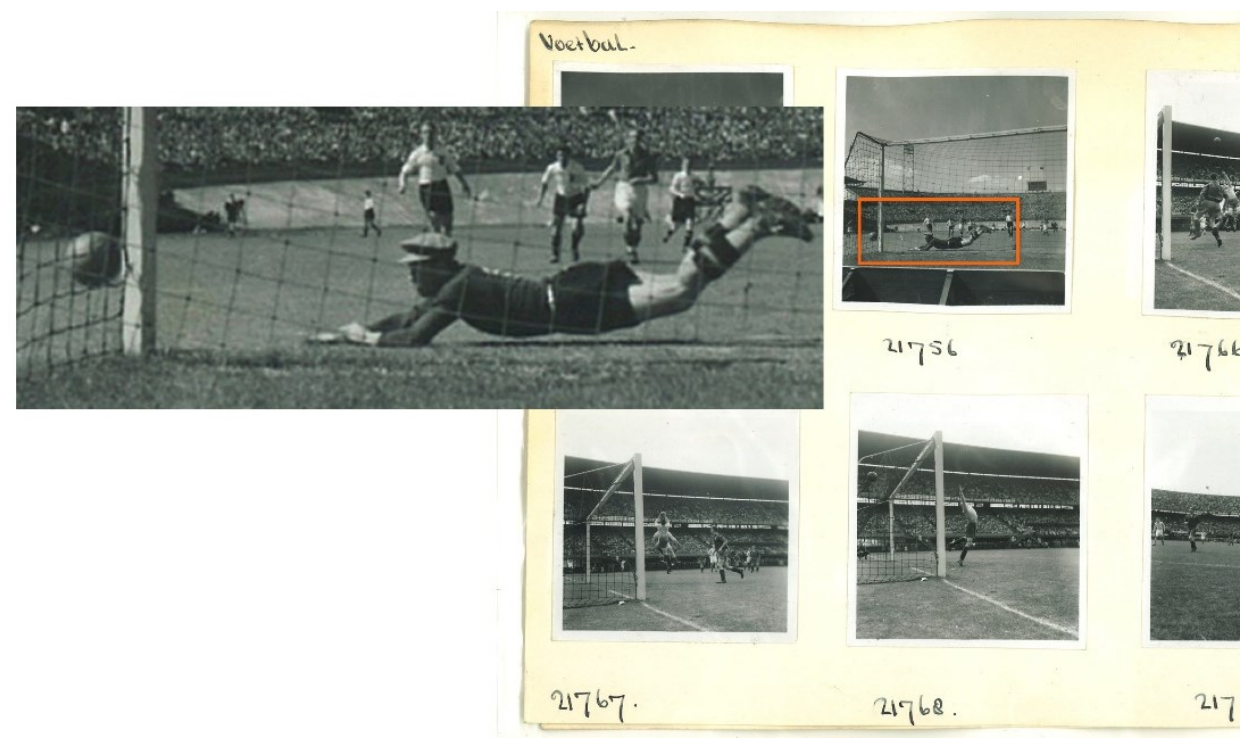

Figure 3. Voetbal contact print no.56 by Kees Molkenboer. (c) Kees Molkenboer / Nederlands Fotomuseum, Rotterdam.

Molkenboer's contact prints show a method of working that requires a highly concentrated level of decision-making, which is not only imposed by the speed of the football match; this acuity is also enforced by the number of exposures he is afforded, the gauge of the film and the type of camera. In contrast to digital photography, film photography is restrictive and unforgiving.

In the moment of photographing a goal, the decisive moment is culturally anticipated by the visual culture of football and the newspaper format. His medium format camera produces $6 \times 6$ square images, yet typically, portrait and landscape images, determined by column sizes, were used in newspapers. Molkenboer prefers to work with this camera but knows that the image he frames will have to contain the action in either a parallel strip or vertical strip, but never horizontal from corner to corner. The conventions of press photography impose a way of seeing and subsequent framing of the game unfolding in front of him. The technical system that this photographer is working within has recalibrated him. There are over two thousand of these football contact print sheets by Molkenboer, each shows more or less the same agenda and formula for photographing the moment of a goal. 


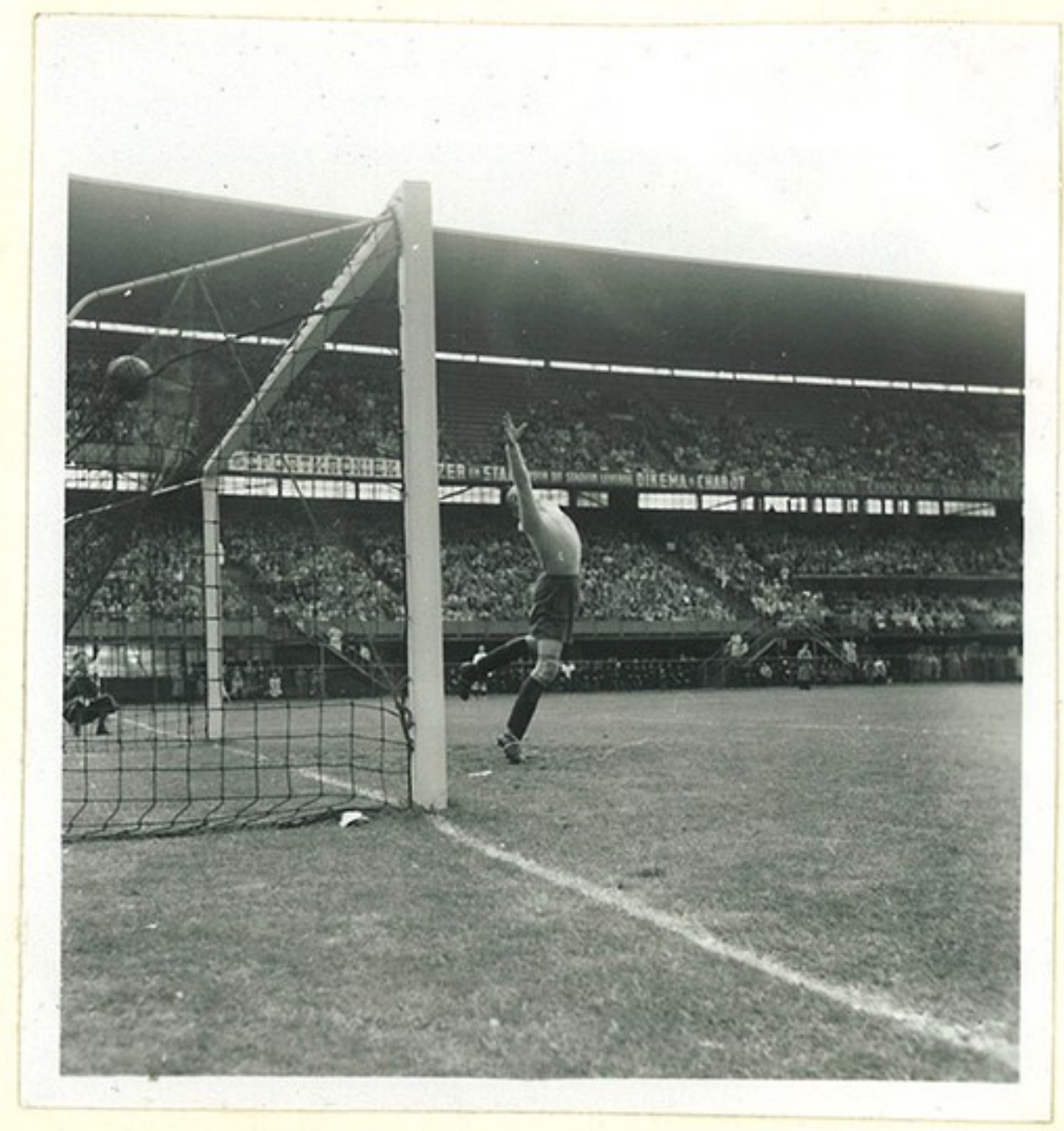

Figure 4. Voetbal contact print no.56 by Kees Molkenboer. (C) Kees Molkenboer / Nederlands Fotomuseum, Rotterdam.

But for a photographer who has never played football, would they be able to get the image of the match in the same way? Their experience would tell them they need to be looking at the ball and not the goalkeeper. Manifested in the contact sheet will always be the phenomenological history of experiences, beliefs, desires and prejudices of the photographer. These past experiences are in constant dialogue with the present moment within which the individual is engaged. For Kees Molkenboer any prior experience of playing or watching football will come to bear upon the moment of depressing the stutter, a complex web of knowledge and experience that factors gravity, 
weight, falling, the particular style and tactics of Dutch football, together with the conventions of sports reportage photography and so on. He will predict where to place himself for the optimum alignment of these dynamics. It's here we witness a curious circuitry, a shared theory of mind between both the photographer and the goalkeeper. The athletic goalkeeper and the athletic photographer, both highly enskilled and actively engaged, their concentration exists purely for the ball. Just as the goalie knows he must watch the ball to predict a goal, the photographer also watches the ball and not the goalkeeper to predict the just-before-moment, in which he will need to depress the shutter to account for the millisecond lag of the camera.

The general thrust of photographic discourse suppresses the randomness, accidental and uncertainty in photographic practices to the smallest size and instead maximizes the intentionality of the photographer as far as it will go. However, if we take the view that photographic artifacts are the manifestation of human engagement with matter and environments, we come to realize that the photograph is not an outcome, nor is it an instant or individually authored action but rather a momentary arrest of many animate meshworks in action. Causality is not a linear process; everything that is ever made comes out of a self-organizing system, which the photographer is part of and responds to. As Manuel DeLanda (1997) states, "there is no one determining agent in a things creation."

The fabled "decisive moment" that was typically attributed to the all-intentional photographer is therefore distributed, it is everywhere at once; there is no one causality. There is a movement in agency and decision making that is distributed amongst all the actors of the meshwork in differing measures, thus shifting the proportionality of decision making. Photography extends the human through a complex network of apparatus and any "decisive moment" is distributed through and amongst that dispositif. Every decision is technologically mediated by a technologically extended mode of seeing which collapses space and time into a new mode of perceiving the world, and this mode of seeing is all part of a contingent system.

\section{References}

Bolt, B., \& Barrett, E. (Eds.). (2012). Carnal knowledge: Towards a 'new materialism' through the arts. London, UK: I.B.Tauris.

Cocozza, P. (2015, January 14). Spot the ball: Why has no jackpot been paid out for 10 years? The Guardian. Retrieved from https://www.theguardian.com/football/shortcuts/2015/jan/14/how-to-spot-the-ball-in-spot-the-ball

DeLanda, M. (1997). A thousand years of nonlinear history. New York, NY: Zone Books.

Ingold, T. (2007). Lines: A brief history. London, UK: Routledge.

Knappett, C., \& Malafouri, L. (Eds.). (2008). Material agency: Towards a non-anthropocentric approach. New York, NY: Springer. 


\section{First response to "A Relational Ecology of Photographic Practices" by Guy Edmonds}

Firstly, I would like to congratulate the author on having unearthed an almost entirely neglected class of media artefact. I think we both share an interest in searching out the most infrequently visited nooks and crannies of the archive. To paraphrase the way in which Joel Pearson described his research during the colloquium as "addicted to discovery," I would say we are "addicted to re-discovery" or perhaps even better, "discovery through re-discovery."

Although study of the contact sheet may be neglected, it does have a popular life as a trope of graphic design, less so today for sure, but I think it could be productive to look at how graphic artists and the odd fine artist such as Richard Hamilton, with his "My Marilyn" series of prints, have appropriated its aesthetic and if there are any instances of the notion of a cognitive trace which have appeared in these graphic or fine art re-workings. Hamilton's print in turn reminded me of Robert Rauschenberg's screenprint paintings, which also seem to be concerned with mental mapping, and I feel sure there must be a body of interpretive work connected with them, although I have not researched this.

It seems to me that in engaging with the contact sheet you are talking about a subset of photographic practices which might be summed up by the term 'reportage.' You are not considering, for example, the mass of amateur photographers on the one hand, or high-end studio photographers using plate cameras on the other, neither group having cause to make use of contact sheets. Or, to take a specific recent example, an artist photographer such as Gregory Crewdson, who uses large format cameras and exerts a vast degree of control over his subjects.

If we consider reportage photographers or artist photographers who are seeking out a vision rather than filling one in, then perhaps we can conceptualize them as riding a flow of experience (within the meshwork that you describe) in an alert state, sensitized and ready for a decisive moment, but not instigating it. I see a kind of tipping point within the meshwork, or rather various different potential tipping points and a good photographer is simply good at finding them, at increasing the chance of a hit. Some of this is down to strategies such as roaming the streets to all hours and taking lots of pictures, but part of it is to do with the photographer's prior experience and internal being. That would be a truly personal cognitive trace which would require more extensive mapping across all surviving contact sheets and many other sources besides. 


\section{Second response to "A Relational Ecology of Photographic Practices” by Pamela Gloria Cajilig}

Jacqui Knight's discussion of co-creation between humans, machines, and environment as meshwork (as borrowed from Ingold, 2007) and call for decentralizing the role of the human in photography signposts important debates about the nature of creativity. Her paper also alludes to the problematic distinctions between "nature" and "culture" that underpin scholarship in the humanities and sciences and which continue to shape divisions in academic disciplines (McLean, 2009 p. 215).

Knight's paper aligns with studies that resist dominant and hylomorphic constructions of creativity that privilege form over relationships and processes (Deleuze \& Guattari, 1980/2004; Gatt \& Ingold, 2013; McLean, 2009). This hylomorphism has moreover led to "an exclusive preoccupation with cultural creativity as a specifically human mode of engagement with the world: that is, regardless of how creativity is defined, it is human beings who alone are shown to practice creativity" (McLean, 2009, p. 214). This view constructs non-humans as simply canvases, tools, and handmaidens of human imagination and endeavor while discounting the possibility of creativity as immanent to the material substance of the universe (Crutzen, 2006; McLean, 2009).

Knight's work also joins a growing body of literature across several disciplines that resists the distinction between "nature" and "culture" and argues for a re-conceptualization of these two spheres in non-oppositional terms (Gunn, Otto, \& Smith, 2013; Haraway et al., 2015; Ingold, 2010). McLean in particular noted how anthropological studies have emphasized the lack of distinction between "nature" and "culture" in many non-Western societies (McLean, 2009, p. 215). Meanwhile, science studies have shown that even in self-styled "modern" Western societies, the definitional separation of nature and culture, along with the institutional separation of the natural and social sciences, has often served to obscure the degree of actual trafficking between the two spheres (McLean, 2009, p. 215).

Meanwhile, the processual and relational approach to creativity encapsulated in Knight's examination of photographic archives certainly has applications beyond the visual arts, and inquiry along this thread can also accommodate different modes of temporality. While Knight employed a historical approach, this formulation of creativity can also apply to speculative endeavor: the urban design initiative "Urban Animals and Us," for example, recognizes the agentic potential of both birds and humans, and experiments with interspecies co-design to explore the possibilities for sustainable futures (Lenksjold \& Olander, 2016). 
As a contribution to Off the Lip 2017, Knight's paper has the potential to provoke reflexive discussions about how the broader environment of knowledge production regarding creativity has led to the reproduction of the usual troublesome distinctions between "nature" and "culture." More importantly, it offers a pluralistic and multi-agent approach to creativity that will hopefully spark transdisciplinary engagement, which would best capture the spirit of Off the Lip 2017.

\section{References}

Crutzen, P. J. (2006). The anthropocene: The current human-dominated geological era. Paths of Discovery, Acta 18.

Deleuze, G., \& Guattari, F. (2004). A thousand plateaus, capitalism and schizophrenia. (B. Massumi, Trans.), London, UK: Continuum. (Original work published 1980)

Gatt, C., \& Ingold, T. (2013). From description to correspondence: Anthropology in real time. In W. Gunn, T. Otto, \& R. C. Smith (Eds.), Design anthropology: Theory and practice (pp. 139-158). London, UK: Bloomsbury Academic.

Gunn, W., Otto, T., \& Smith, R. C. (Eds.). (2013). Design anthropology: Theory and practice. London, UK: Bloomsbury Academic.

Haraway, D., Ishikawa, N., Gilbert, S. F., Olwig, K., Tsing, A. L., \& Bubandt, N. (2015). Anthropologists are talking: About the anthropocene. Ethnos, 81(3), 535-564. doi:10.1080/00141844.2015.1105838

Ingold, T. (2007). Lines: A brief history. London, UK: Routeledge

Ingold, T. (2010). The textility of making. Cambridge Journal of Economics, 34(1), 91-102. doi:10.1093/cje/bep042

Lenksjold, T. U., \& Olander, S. (2016). Design anthropology as ontological exploration and interspecies engagement. In R. C. Smith, K. T. Vangkilde, M. G. Kjærsgaard, T. Otto, J. Halse, \& T. Binder (Eds.), Design anthropological futures. London, UK: Bloomsbury.

McLean, S. (2009). Stories and Cosmogenies: Imagining Creativity Beyond 'Nature' and 'Culture'. Current Anthropology, 24(2), 213-245. 


\section{Third response to "A Relational Ecology of Photographic Practices” by Michael Punt}

This is a closely argued and well-honed discussion that tries to retrofit an understanding of photography as a manifestation of human engagement with matter. It draws benefit from the new insights that machine vision, digital photography, and photographic simulation can yield. Its intervention is in the extent to which it refigures the pre-digital practices of photography as an inevitable feature of both human social predisposition for co-production (collaboration) and an apparently equally irresistible cultural predisposition to disavow such co-production. From this, the paper suggests-but does not develop-a line of argument that creativity may owe much to the contradictory tensions between these two. In this sense, the paper offers an insight into collaboration and creativity that is original. The author develops some key texts in ways that are grounded in the texts and also provocative (Ingold, Da Landa), and certainly beyond what the original authors envisaged.

The paper is simply written for such an ambitious conceptual challenge and clear to follow. There is a suggestion in the text that just as the current photographic practices have revealed something of the concealed strategies of the past, so as the paper is developed, its extent and intervention might also become clearer. 


\section{Fourth response to "A Relational Ecology of Photographic Practices" by Mark-Paul Meyer}

Largely been informed by a dominant anthropocentric narrative, Knight's premise that Western culture and philosophy - and subsequently art history and the history of photography - creates a fascinating opportunity to study photography in a new and challenging way. It reminds us of the fact that art history has been shaped by a limited number of books that have gained authority over the last century. That art history may consist of many narratives of which many have been systematically overlooked is probably one of the most challenging research areas for the coming years. Knight is taking an important step when she puts traditional concepts and questions of originality, genius, authenticity, artists' intention and authorship, the artefact and the masterpiece on a side-track to allow new questions and issues to come to the foreground. Knight challenges the concept of the all-powerful artistphotographer by studying contact sheets and, consequently, the complex interaction between humans, artefacts and machines. You could say that Knight creates a "method" to "read" contact sheets, and deducts from these sheets the creative and decision-making process of the photographer.

Knight refers to the meshwork as described by Ingold and distinguishes it from the Latourian network theory in stating that the relationships are more important than the nodes. It may become clearer from the close reading of Molkenboer's contact sheets, but from the text it is not immediately clear why the one model privileges over the other model, or even what the differences exactly are.

The questions that stick to my mind are whether the analysis of contact sheets may not only help to define and fine-tune a model of interactions, but whether it also allows to distinguish new narratives and what examples of narratives we could think of? In other words: will this 'method' allow to (re-)write the history of photography focusing on narratives that have long-lasting been ignored or neglected?

It would also be interesting to know whether other research areas can be identified that allow for the study of 'unknown' narratives. For instance, personal archives of photographers, which may be organized in completely different way before they are swallowed by the conformity of official archives. Or, I can also think of stacks of printed photographs that have been printed but have not been used for publication. Or dummies of photobooks.

A critical question regards Knights conclusion that the photograph is not an individually authored action but "rather a momentary arrest of many animate meshworks in action" (p. 291). The question is then how this 'momentary arrest' is realized, other than by the photographer who - being part of the meshwork - decides to freeze the activity of the meshwork and pushes the button of the camera. This brings us back to 
anthropocentrism which may undermine Knight's argumentation. Or does she see her argumentation in the line of new materialism, and would she consider the meshwork to be a kind of organism, a subject that interacts and speaks to us. But the question remains to whom the meshwork relates? To the photographer? 